\title{
Longer Delays in Diagnosis and Treatment of Pulmonary Tuberculosis in Pastoralist Setting, Eastern Ethiopia
}

This article was published in the following Dove Press journal: Risk Management and Healthcare Policy

\author{
Fentabil Getnet (iD) ${ }^{1,2}$ \\ Meaza Demissie (iD ${ }^{3}$ \\ Alemayehu Worku (iD) 3,4 \\ Tesfaye Gobena ${ }^{2}$ \\ Rea Tschopp ${ }^{5-7}$ \\ Berhanu Seyoum ${ }^{5}$ \\ 'College of Medicine and Health \\ Sciences, Jigjiga University, Jigjiga, \\ Ethiopia; ${ }^{2}$ School of Public Health, \\ Haramaya University, Harar, Ethiopia; \\ ${ }^{3}$ Addis Continental Institute of Public \\ Health, Addis Ababa, Ethiopia; ${ }^{4}$ School of \\ Public Health, Addis Ababa University, \\ Addis Ababa, Ethiopia; ${ }^{5}$ Armauer Hansen \\ Research Institute, Addis Ababa, Ethiopia; \\ ${ }^{6}$ Department of Epidemiology and Public \\ Health, Swiss Tropical and Public Health \\ Institute, Basel, Switzerland; ${ }^{7}$ University \\ of Basel, Basel, Switzerland
}

Purpose: This study aimed to assess the extent of patient, health system and total delays in diagnosis and treatment of pulmonary tuberculosis (TB) in Somali pastoralist setting, Ethiopia.

Patients and Methods: A cross-sectional study among 444 confirmed new pulmonary TB patients aged $\geq 15$ years in 5 TB care units was conducted between December 2017 and October 2018. Data were collected using a structured questionnaire and record review. We measured delays from symptom onset to provider visit, provider visit to diagnosis and diagnosis to treatment initiation. Delays were summarized using median days. MannWhitney and Kruskal-Wallis tests were used to compare delays between categories of explanatory variables. The Log-binomial regression model was used to reveal factors associated with health system delay $\geq 15$ days, presented in adjusted prevalence ratio (APR) with 95\% confidence interval (CI).

Results: The median age of patients was 30 years, ranged from 15 to 82 . The majority $(62.4 \%)$ were male, and nearly half $(46.4 \%)$ were pastoralists. The median patient, health system and total delays were 30 (19-48.5), 14 (4.5-29.5) and 50 (35-73.5) days, respectively. The median patient delay (35.5 days) and total delay (58.5 days) among pastoralists were substantially higher than the equivalent delays among non-pastoralists $[\mathrm{p}<0.001]$. Of all, $3.8 \%$ of patients (16 of 18 were pastoralists) delayed longer than 6 months without initiating treatment. Factors associated with health system delay $\geq 15$ days were mild symptoms $[$ APR $(95 \% \mathrm{CI})=1.4(1.1-1.7)]$, smear-negativity $[$ APR $(95 \% \mathrm{CI})=1.2(1.01-$ $1.5)]$, first visit to health centers $[\mathrm{APR}(95 \% \mathrm{CI})=1.6(1.3-2.0)]$ and multiple provider contacts [APR $(95 \% \mathrm{CI})=5.8(3.5-9.6)]$.

Conclusion: Delay in diagnosis and treatment remains a major challenge of tuberculosis control targets in pastoralist settings of Ethiopia. Efforts to expand services tailored to transhumance patterns and diagnostic capacity of primary healthcare units need to be prioritized.

Keywords: patient delay, health system delay, total delay, tuberculosis, pastoralist

\section{Introduction}

Tuberculosis (TB) is a disease caused by Mycobacterium tuberculosis. Globally, an estimated 10 million people got ill with TB, and over 1.4 million died from the disease in 2018. Ethiopia is one of the highly affected countries, ranking 9th among the high burden countries, 3rd in Africa, and one of the few countries with triple TB, multi-drug resistant TB (MDR-TB) and TB/HIV burden. ${ }^{1}$ The national TB survey indicated that pastoral communities had the highest toll of TB prevalence in Ethiopia. ${ }^{2}$ The global
Correspondence: Fentabil Getnet Jigjiga University, P. O. Box I020, Jigjiga, Ethiopia

Tel +25I 913289380

Email b.infen4ever@gmail.com 
End-TB Strategy relies on early diagnosis and treatment of cases as a principal tool to improve patient outcomes, prevent drug resistance, interrupt transmission, and ultimately to end TB epidemics by $2030 .^{3}$ The national TB control program (NTP) of Ethiopia primarily strives to achieve this target through effective detection of symptomatic TB cases who present themselves to health facilities, also known as passive case-finding strategy. ${ }^{4}$

This widely used passive approach in resource-limited settings, however, flunks to bring the planned case detection rates, as a result, millions of $\mathrm{TB}$ cases are missed from being detected. ${ }^{5,6}$ In Ethiopia, over a third of the estimated 165,000 TB cases were not notified and treated in 2018. ${ }^{1}$ A large number of cases are missed; community-based studies in the country have indicated the magnitude of undetected TB cases in communities could be equal or larger than notified cases. ${ }^{6,7}$ Despite the drastic expansion of health services in the Somali Regional State of Ethiopia, the case detection rate remained the lowest at $34 \%$ in 2015 given the target was $70 \%$ and has not surpassed $50 \%$ in subsequent years. ${ }^{8}$ The ineffectiveness of this passive process in achieving the required case detection rates could be due to the poor healthcare-seeking practice of symptomatic patients, or could be due to the health system capability to examine and detect presented cases. ${ }^{9,10}$ This denotes medical help-seeking behavior of patients, accessibility of quality diagnostic facilities, and competence and efficiency of healthcare providers to suspect and investigate presumptive TB cases are crucial to ensure early diagnosis and treatment initiation.

However, patients' delay in seeking medical help and health system's delay in detecting TB cases presented to health facilities has remained problematic to case detection efforts in resource-limited settings. The extent of delays, substantially attributable to both the patients and health system, could be as long as several weeks, months, or even more than a year and varies in different geographical, epidemiological and socio-political settings. ${ }^{9}$ In Ethiopia, delays fluctuate across settings; from a median delay of 41 days in Northern ${ }^{11}$ to 45 days in Southern ${ }^{12}$ and 60 days in North-western areas. ${ }^{13}$ A decade ago, median delay exceeding two months and a maximum of 2 years delay had also been reported in pastoralist settings. ${ }^{14}$ Failure to timely detect and treat active TB cases affects patients, community and the healthcare system. Extreme delays exacerbate disease severity, advance dissemination, prolong patient suffering, increase fatality and adverse treatment outcomes such as failure and drug resistance. It also fuels disease transmission to close contacts. ${ }^{15,16}$ The healthcare system will be burdened leading to extra healthcare costs to treat complicated disease forms. ${ }^{17}$

Therefore, assessing delays in TB care, and identifying impediments in settings where passing case-finding is the leading strategy is very important. Moreover, it is indispensable in areas where TB is very prevalent but the case detection rate is still very low. Thus, this study was aimed to assess the extent of patient, health system and total delays in diagnosis and treatment of pulmonary TB in the Somali pastoralist setting, Eastern Ethiopia.

\section{Patients and Methods}

\section{Study Setting}

This study was conducted in the Somali regional state of Ethiopia. In the region, more than $85 \%$ of the population resides in rural areas, and lead either nomadic or agropastoral way of life. ${ }^{18}$ Pastoralism is the main means of subsistence of the community. ${ }^{19}$ Nomadic pastoralists rear livestock and undergo seasonal transhumance movements, and agro-pastoralists are engaged in mixed herding and farming. ${ }^{14,20}$ In the setting, 10 hospitals and some selected health centers provide TB diagnosis and treatment services according to the national guideline. ${ }^{4}$ Diagnosis of Pulmonary TB (PTB) includes smear microscopy, GeneXpert, chest radiographs, pathological and clinical investigations. Treatment is provided according to the national strategy, Directly Observed Treatment-Short course (DOTS). This study was conducted in four hospitals (Kharamara, Degehabour, Kebri-daher, and Gode) and in one health center (Abilelie) found in the region. These facilities were selected based on their high patient flow, presence of radiologic facilities and wider geographical coverage.

\section{Study Design and Population}

A facility based cross-sectional study was conducted between December 2017 and October 2018. Newly diagnosed PTB patients and aged $\geq 15$ years were included irrespective of smear status and history of TB treatment. This age category was chosen because patients $\geq 15$ years of age manifest similar pathological features, and the same diagnostic algorithm is followed. ${ }^{4}$ It is also the transition from childhood to youth/adulthood at which people start seeking care for their health demands.

\section{Sample Size and Sampling Procedure}

The minimum sample size calculated was 413 using OpenEpi303 software for a single proportion in a population. 
Estimation parameters were 95\% confidence interval, $80 \%$ power, $42 \%$ of PTB patients delayed above 30 days in lowand middle-income countries, ${ }^{9} 5 \%$ precision and $10 \%$ nonresponse rate. Adding up the available patients during the study period yielded 444 patients as the final sample size. All newly confirmed PTB patients and aged $\geq 15$ years were recruited prospectively starting from the initiation of the study. Recruitment was done at DOTS clinics of the respective study facilities as confirmed PTB patients arrived at the clinic to initiate treatment while they had the sore illness before initiation of therapy.

\section{Data Collection}

Data were collected using a pre-tested structured questionnaire administered by interviewers. Patient records were also reviewed to gather information on clinical characteristics and to crosscheck patient-reported clinical data. The questionnaire was adapted from the World Health Organization (WHO) study on diagnostic and treatment delays in the Eastern Mediterranean region, ${ }^{21}$ and similar studies in Ethiopia and abroad. ${ }^{14,22-24}$ It was translated into local Somali and Amharic languages by two language experts for each language, and inconsistencies were resolved through mutual agreement. Nurses in the respective DOTS clinics conducted interviews and record reviews after the provision of training on study objectives, sampling procedures, interview techniques, questionnaire contents, and ethical conformity. Interviewing patients about the history of their illness might induce recall bias; therefore, to alleviate this problem, we used the following approaches. The first was interview time; patients were recruited immediately as they arrived at the DOTS clinic and before initiation of treatment. This was to minimize recall bias that would happen if patients were asked after illness recovery upon treatment initiation. The second was the interview approach to measure time delays; the critical first dates of symptom onset, medical consultation and diagnosis were asked rather than asking the patients to recall the number of days they delayed. Patients were first asked to list the symptoms they had and the dates each symptom started. Then they were asked the date of first healthcare provider consultation, and the date they were diagnosed as PTB patients. If patients were uncertain of the critical dates, they were encouraged to associate with notable religious or cultural events. Information was also crosschecked by reviewing patient cards. The durations of delays (patient, health system, diagnosis, treatment and total) were calculated using the characteristic dates of symptom onset, provider consultation, diagnosis, and treatment initiation.

Also, sputum smears were transported and examined blindly by experienced laboratory technologists at Armauer Hansen Research Institute laboratory in Addis Ababa, Ethiopia. It was done to assess the quality of microscopic examinations and the capacity of laboratory technologists to detect acid-fast bacilli using Ziehl Neelsen staining technique at peripheral health facilities.

\section{Measurements}

Patient delay: is defined as the time interval (days) between the onset of a symptom(s) related to PTB and the first date the patient consulted a healthcare provider at a health center or hospital or private facilities with TB diagnosis and treatment services. This excluded drug vendors, health posts and traditional healers. Cough was used as a benchmark of symptom onset, but other main symptoms that compelled the patient to seek healthcare were considered in the absence of cough.

Health system delay: is defined as the time interval (days) between the patient's first consultation to a healthcare provider and the date of diagnosis as PTB patient. Health system delay was dichotomized at 14 days cutoff ("non-delayed" if $\leq 14$, and "delayed" if $\geq 15$ ) considering two weeks delay as a programmatically tolerable if TB cases had a smear-negative result at the initial examination; otherwise, should be diagnosed in lesser time.

Diagnosis delay: is defined as the time interval (days) between the onset of pulmonary illness and the date of diagnosis as PTB patient (sum of patient and health system delays).

Treatment delay: is defined as the time interval (days) from the date of diagnosis to treatment initiation.

Total delay: is defined as the total time interval (days) between the onset of a symptom(s) related to PTB to date of treatment initiation. (Figure 1)

\section{Data Processing and Analysis}

All data were double entered using EpiData 3.1 and analyzed using Stata version 14 (StataCorp, College Station, Texas 77,845 USA). Data were summarized in frequencies and median/mean depending on the type of variables. Median and inter-quartile range (IQR) were used to summarize patient, health system and total delays in diagnosis and treatment of TB. As delays were skewed, nonparametric Mann-Whitney and Kruskal-Wallis tests were 


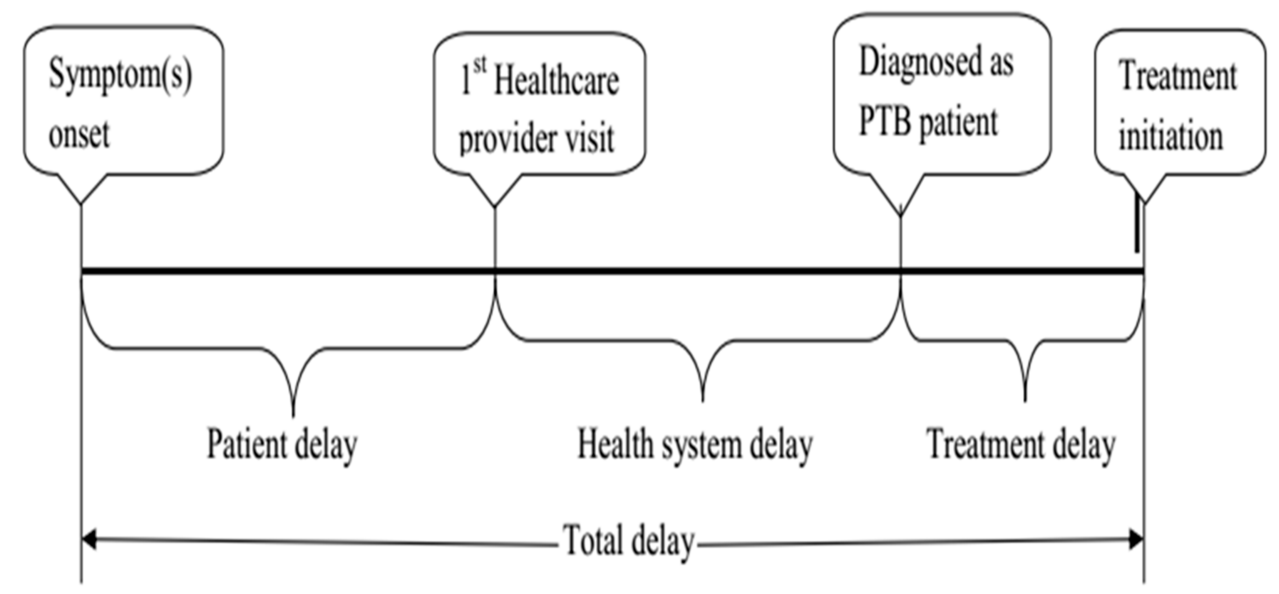

Figure I Components of delays in diagnosis and treatment of pulmonary tuberculosis.

used to compare patient and health system delays between categories of explanatory variables. Mann-Whitney test was used to compare delays between two categories of an explanatory variable, and Kruskal-Wallis if a variable had three or more groups. Box plots were used to illustrate patient/total delays between pastoral and non-pastoral patients, and health system delay between patients who sought first care at health centers and hospitals. In addition, we evaluated patient (clinical and socio-demographic) and structural (health system-related) factors associated with health system delay. The Log-binomial regression model was employed to reveal factors associated with health system delay $\geq 15$ days. Statistical significance was determined at $\mathrm{P} \leq 0.05$, and $\mathrm{P} \leq 0.2$ in the bivariate analysis was the cutoff to include variables in the final multivariable model. Estimates are presented in prevalence ratios with $95 \%$ confidence intervals.

\section{Results}

\section{Socio-Demographic Characteristics}

In total, 444 newly diagnosed pulmonary TB patients were recruited from four hospitals and one health center between December 2017 and October 2018. The median age of participants was $30(\mathrm{IQR}=23-50)$ years, ranged 15 to 82 years. The majority $(62.4 \%)$ of the patients were male, illiterate $(61.7 \%)$, and younger than 35 years constituted $58.1 \%$. Nearly half $(46.4 \%)$ were pastoralists, of which, $35.9 \%$ were nomadic. Concerning access to health services, the median one-way walking time from patients' dwelling to the nearest health facility was 40 minutes $(\mathrm{IQR}=20-120$ minutes $)$, ranged 5 minutes to 720 minutes;
4 rural patients traveled 720 minutes (full day) to reach TB care units (Table 1).

\section{Clinical Characteristics}

The majority of patients were new cases (90.1\%), smearnegative $(57.9 \%)$, had an ambulatory physical condition $(77.0 \%)$, and $2.3 \%$ were TB/HIV co-infected. Of the main TB-related symptoms, the commonly manifested symptoms in the course of the disease were cough $(97.1 \%)$, chest pain $(63.7 \%)$, fatigue $(43.5 \%)$, night sweating $(42.6 \%)$ and weight loss $(35.4 \%)$. At the first presentation to a healthcare provider, the majority of patients presented with cough $(91.0 \%)$ and chest pain (56.8\%). TB-related symptoms including hemoptysis, chest pain, fatigue, fever, dyspnea, and smear positivity were higher in patients with longer patient delay (Table 2).

\section{Extents of Delays in Diagnosis and Treatment of Pulmonary Tuberculosis Patient Delay}

The median patient delay from the onset of pulmonary illness to the first provider visit was 30 days ( $\mathrm{IQR}=19-48.5$ days), ranged from 2 days to 330 days. Of the total, only $14.2 \%$ and $30.4 \%$ sought medical attention within the recommended two and three weeks of pulmonary illness (cough), respectively. Median patient delays were higher in illiterate, rural, pastoral and patients with long walking distance (Mann-Whitney/ Kruskal-Wallis tests, $p<0.05$ ) (Table 1 ). The median patient delay of 35.5 days (IQR=23 - 66 days) among pastoralist patients was higher than 27.5 days (17.5 - 43 days) among urban/sub-urban patients [Mann-Whitney test, $p<0.001$ ] (Figure 2). Of the total 444 patients, 11 pastoralists $(2.5 \%)$ 
Table I Socio-Demographic Characteristics with Corresponding Patient and Health System Delays of PTB Patients in Somali Region, Eastern Ethiopia, December 2017 to October $2018(n=444)$

\begin{tabular}{|c|c|c|c|c|c|}
\hline \multirow[t]{2}{*}{ Characteristics $(n=444)$} & \multirow[t]{2}{*}{ Frequency (\%) } & \multicolumn{2}{|c|}{ Patient Delay } & \multicolumn{2}{|c|}{ Health System Delay } \\
\hline & & Median & P-value & Median & P-value \\
\hline \multicolumn{6}{|l|}{ Sex } \\
\hline Male & $277(62.4)$ & $30(19-48)$ & 0.70 & $15(4-30)$ & 0.15 \\
\hline Female & $167(37.6)$ & $30(19-49)$ & & $13(5-26)$ & \\
\hline \multicolumn{6}{|l|}{ Age group } \\
\hline 15 to 23 & $118(26.6)$ & $30(19-45)$ & 0.91 & $13(4-23)$ & 0.65 \\
\hline 24 to 30 & 115 (25.9) & $30(18-46)$ & & $15(5-30)$ & \\
\hline 31 to 50 & $125(28.2)$ & $32(20-50)$ & & $15(5-30)$ & \\
\hline $51+$ & $86(19.4)$ & $26.5(20-53)$ & & $12.5(4-30)$ & \\
\hline \multicolumn{6}{|l|}{ Literacy level } \\
\hline Illiterate & $274(6 \mid .7)$ & $32(2 \mid-56)$ & 0.01 & $13(5-29)$ & 0.5 \\
\hline Primary & $46(10.4)$ & $28.5(15-43)$ & & II (4-25) & \\
\hline Secondary & $66(14.9)$ & $28(16-40)$ & & $18.5(4-33)$ & \\
\hline Tertiary & $58(13.1)$ & $29(13-43)$ & & $14.5(5-28)$ & \\
\hline \multicolumn{6}{|l|}{ Marital status } \\
\hline Single & $133(29.9)$ & $30(18-42)$ & 0.33 & $14(5-28)$ & 0.03 \\
\hline Married & $272(6 \mid .3)$ & $29(19.5-53)$ & & $12.5(4-28.5)$ & \\
\hline Divorced/widowed & $39(8.8)$ & $32(22-50)$ & & $22(12-33)$ & \\
\hline \multicolumn{6}{|l|}{ Residence } \\
\hline Rural & $219(49.3)$ & $35(22-6 I)$ & $<0.001$ & $13(4-30)$ & 0.29 \\
\hline Urban & $221(49.8)$ & $27(17-42)$ & & $15(6-29)$ & \\
\hline Refugee/displaced & $4(0.9)$ & $\phi \phi$ & & $\phi \phi$ & \\
\hline \multicolumn{6}{|l|}{ Livelihood } \\
\hline Pastoralism & $206(46.4)$ & $35.5(23-66)$ & $<0.001$ & $13.5(4-30)$ & 0.48 \\
\hline Non-pastoralism & $238(53.6)$ & $27.5(17-43)$ & & $14(5-29)$ & \\
\hline \multicolumn{6}{|l|}{ Income } \\
\hline Saving & $57(12.8)$ & $30(19-51)$ & 0.09 & $20(7-30)$ & 0.11 \\
\hline Income=expense & $309(69.6)$ & $32(20-50)$ & & $14(4-27)$ & \\
\hline Indebt & $78(17.6)$ & $26(|6-4|)$ & & $13(5-33)$ & \\
\hline \multicolumn{6}{|l|}{ Access to nearest health facility (one-way) } \\
\hline An hour or less & $307(69.1)$ & $27(|7-4|)$ & $<0.001$ & $12(4-25)$ & 0.01 \\
\hline One to two hours & $60(13.5)$ & $36.5(23-58)$ & & $17.5(7.5-38)$ & \\
\hline More than two hours & $77(17.4)$ & $56(28-77)$ & & $17(4-30)$ & \\
\hline \multicolumn{6}{|l|}{ A family member with a history of TB } \\
\hline Yes & $90(20.3)$ & $30(22-48)$ & 0.36 & $13(4-30)$ & 0.68 \\
\hline No & $34 \mid(76.8)$ & $30(18-50)$ & & $14(5-29)$ & \\
\hline Do not know & $13(2.9)$ & $\phi \phi$ & & & \\
\hline
\end{tabular}

Note: "The response category is dropped out of the analysis.

had patient delay longer than six months ( $\geq 168$ days). Patients had taken various actions following the onset of illness; $76.5 \%$ (338/442) visited healthcare facilities, $12.9 \% \quad(57 / 442)$ attempted traditional/self-remedy, 9.5\% (42/442) visited drug vendors and $1.1 \%(5 / 442)$ visited health extension workers. The reasons to opt for the informal care were perceived long waiting time/crowdedness at health facilities $(32.7 \%)$, lack of confidence in the quality of services $(9.6 \%)$, fear of service costs $(5.8 \%)$, the remoteness of health facilities $(25 \%)$, bad experience in the past $(24 \%)$, and others $(2.9 \%)$. The decision to visit healthcare provider was made by patients' self-decision (52.7\%), upon advice from family/close people 
Table 2 Clinical Characteristics with Corresponding Patient and Health System Delays of PTB Patients in Somali Region, Eastern Ethiopia, December 2017 to October $2018(n=444)$

\begin{tabular}{|c|c|c|c|c|c|}
\hline \multirow[t]{2}{*}{ Characteristics $(n=444)$} & \multirow[t]{2}{*}{ Frequency (\%) } & \multicolumn{2}{|l|}{ Patient Delay } & \multicolumn{2}{|c|}{ Health System Delay } \\
\hline & & Median & P-value & Median & P-value \\
\hline \multicolumn{6}{|l|}{ Functional status } \\
\hline Good & $88(19.8)$ & $30.5(19-43.5)$ & 0.41 & $12.5(5-2 \mid .5)$ & 0.08 \\
\hline Ambulatory & $342(77.0)$ & $30(19-53)$ & & $15(5-30)$ & \\
\hline Bedridden & $14(3.2)$ & & & & \\
\hline \multicolumn{6}{|l|}{ Treatment category } \\
\hline New & $400(90.1)$ & $30(19.5-48.5)$ & 0.53 & $14(4.5-30)$ & 0.79 \\
\hline Retreatment & $44(9.9)$ & $32(17-48)$ & & I $4.5(4.5-27)$ & \\
\hline \multicolumn{6}{|l|}{ History of TB } \\
\hline Yes & $64(14.4)$ & $32(18-50)$ & 0.89 & $12.5(5-29.5)$ & 0.98 \\
\hline No & $380(85.6)$ & $30(19.5-48)$ & & $14(4-29.5)$ & \\
\hline \multicolumn{6}{|l|}{ Smear status } \\
\hline Positive & $187(42.1)$ & $37(23-53)$ & $<0.001$ & $10(3-27)$ & $<0.001$ \\
\hline Negative & $257(57.9)$ & $26(17-44)$ & & $16(7-30)$ & \\
\hline \multicolumn{6}{|l|}{ Symptoms in the course of the disease } \\
\hline Cough & $431(97.1)$ & $30(19-50)$ & 0.45 & $14(4-30)$ & 0.87 \\
\hline Hemoptysis & $35(7.9)$ & $47(25-70)$ & 0.004 & $6(2-23)$ & 0.02 \\
\hline Chest pain & $283(63.7)$ & $32(20-5 I)$ & 0.05 & $15(4-29)$ & 0.78 \\
\hline Dyspnea & $97(21.9)$ & $33(22-50)$ & 0.23 & $13(5-30)$ & $0.8 \mathrm{I}$ \\
\hline Weight loss & $157(35.4)$ & $29(19-50)$ & 0.84 & $9(3-19)$ & $<0.001$ \\
\hline Night Sweating & $189(42.6)$ & $34(20-54)$ & 0.06 & II (4-26) & 0.01 \\
\hline Fatigue & $193(43.5)$ & $35(2 \mid-56)$ & 0.02 & $10(3-23)$ & $<0.001$ \\
\hline Fever & $119(26.8)$ & $32(19-63)$ & 0.13 & $6(2-25)$ & $<0.001$ \\
\hline Appetite loss & $102(23.0)$ & $34(20-58)$ & 0.18 & $6(2-19)$ & $<0.001$ \\
\hline \multicolumn{6}{|l|}{ Symptoms at first provider visit } \\
\hline Cough & $404(91.0)$ & $30(18-49.5)$ & 0.68 & $13(4-28.5)$ & 0.01 \\
\hline Hemoptysis & $32(7.2)$ & $47(25-70)$ & 0.004 & $6(2-23)$ & 0.02 \\
\hline Chest pain & $252(56.8)$ & $32(20-5 \mid .5)$ & 0.1 & $14(4-27)$ & 0.10 \\
\hline Dyspnea & $61(13.7)$ & $35(23-58)$ & 0.05 & $9(2-29)$ & 0.21 \\
\hline Fatigue & $189(42.8)$ & $32(20-5 I)$ & 0.27 & II (4-25) & 0.01 \\
\hline Fever & $129(29.0)$ & $35(23-52)$ & 0.01 & $9(2-30)$ & 0.04 \\
\hline \multicolumn{6}{|l|}{ HIV status } \\
\hline Positive & $10(2.3)$ & $37(2 \mathrm{I}-46)$ & 0.9 & $28.5(14-46)$ & 0.06 \\
\hline Negative & $432(97.3)$ & $30(19-50)$ & & $14(4-29)$ & \\
\hline & $2(0.4)$ & $\phi \phi$ & & & \\
\hline
\end{tabular}

Note: ${ }^{\phi \phi}$ The response category is dropped out of the analysis.

(45.3\%), and the rest (2.0\%) were referred by health extension workers, traditional healers and drug vendors.

\section{Health System Delay}

The median health system delay from the first healthcareprovider consultation to diagnosis was 14 days (IQR $=4.5-29.5$ days), ranged from 1 day to 98 days. Following healthcare provider consultation, $48.4 \%$ of patients were not detected as PTB patients within two weeks of consultation (the programmatically tolerable delay if a patient was AFB smearnegative at initial examination). Of all, $49.6 \%$ of patients had an initial consultation at health centers, $45.7 \%$ at hospitals, while $4.7 \%$ at private clinics with TB diagnosis services. The median health system delays were 17.5, 8.0 and 28.0 days among patients who made the first consultation in health centers, hospitals, and private clinics, respectively (KruskalWallis test, $p<0.001$ ) (Figure 3). The median number of health facility encounters was $2(\mathrm{IQR}=1-3)$; patients contacted 1 to 


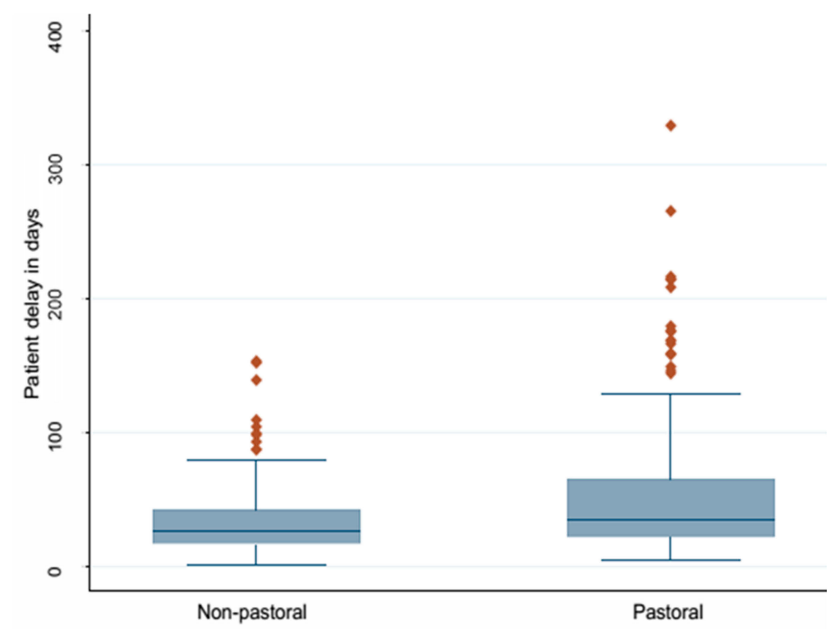

Figure 2 Patient delay among pastoralist and non-pastoralist PTB patients in Somal Region of Ethiopia, December 2017 to October 2018.

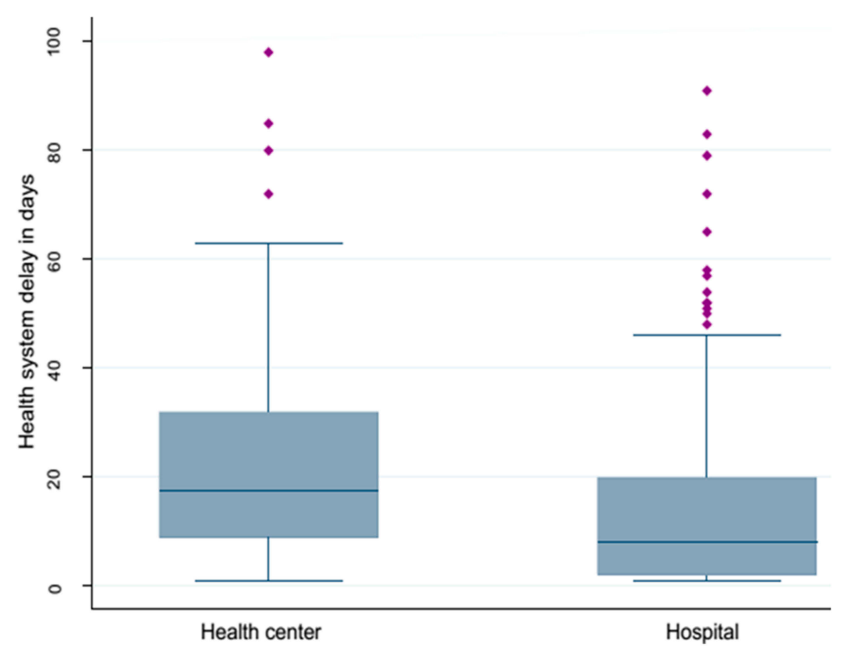

Figure 3 Health system delay among PTB patients who sought the first consultation in health centers and hospitals in Somali Region of Ethiopia, December 2017 to October 2018 .

6 health facilities before being confirmed as PTB patient. The median health system delay was higher in smear-negative (16 days) than smear-positive (10 days) (Mann-Whitney test, $p<0.001$ ); whereas patients presented with cough, hemoptysis, fatigue, and fever had shorter median health system delays (Mann-Whitney test, $p<0.05$ ) (Table 2).

\section{Total Delays to TB Diagnosis and Treatment}

The median diagnosis delay from onset of pulmonary illness to diagnosis (sum of patient and health system) was 49 days $(\mathrm{IQR}=33.5-71.5$ days $)$, ranging from 8 days to 362 days, and the median treatment delay from diagnosis to treatment initiation was 1 day (IQR $=1-2$ days), ranged from 1 day to 18 days. The median total delay from the onset of pulmonary

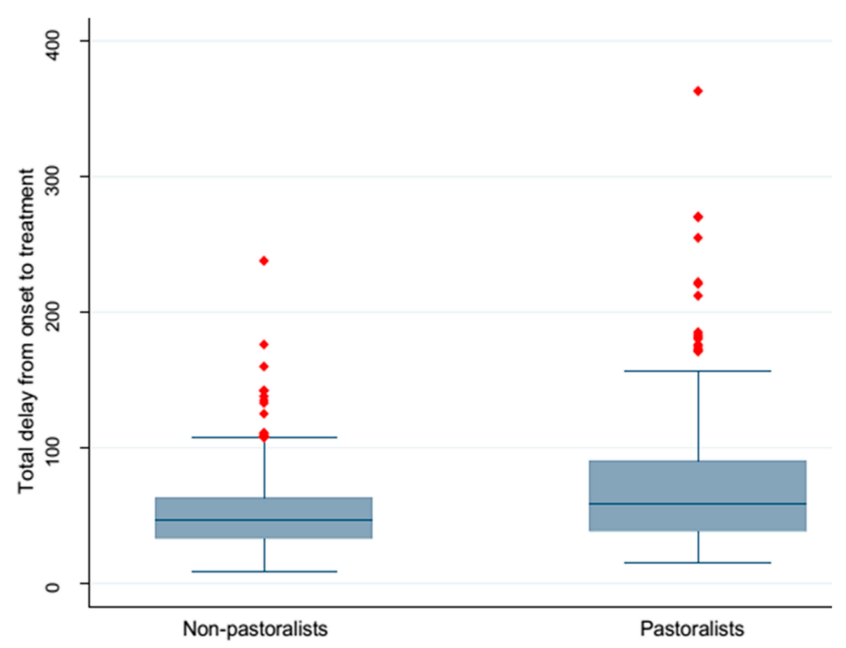

Figure 4 Total delay among pastoralist and non-pastoralist PTB patients in Somali Region of Ethiopia, December 2017 to October 2018.

illness to treatment initiation was 50 days (IQR $=35-73.5$ days), ranged from 9 days to 363 days. Of all, $82.4 \%$ of patients experienced a delay longer than a month and $3.8 \%$ of patients (16 pastoralists and 2 non-pastoralists) longer than six months prior to treatment initiation. The median total delay of 58.5 days ( $\mathrm{IQR}=38$ - 90 days) among pastoralist patients was significantly higher compared to 46.5 days $(\mathrm{IQR}=33-63$ days) among urban patients [Mann-Whitney test, $p<0.001]$. (Figure 4 )

\section{Factors Associated with Health System Delay}

After adjusting for potential confounders, the health system delay $\geq 15$ days was associated with clinical and health system related factors. Of the patient factors, health system delay $\geq 15$ days was associated with the manifestation of only two or fewer symptoms [APR $(95 \% \mathrm{CI})=1.4(1.1-1.7)]$, smearnegative results at diagnosis $[\mathrm{APR}(95 \% \mathrm{CI})=1.2(1.01-$ $1.5)]$, and multiple $(\geq 2)$ provider visits $[\mathrm{APR}(95 \% \mathrm{CI})=5.8$ (3.5 - 9.6)] compared to patients with multiple symptoms, smear-positive result, and diagnosed at the first visit, respectively. Of the structural factors, health system delay $\geq 15$ days was higher in patients who made the first visit to health centers $[\mathrm{APR}(95 \% \mathrm{CI})=1.6(1.3-2.0)]$ compared to patients who sought first care at hospitals. Upon rechecking of sputum smears at the referral laboratory, $19.2 \%$ of smearpositive and $2.9 \%$ of smear-negative results were misdiagnosed in health centers or hospitals. (Table 3)

\section{Discussion}

In this study, the median patient, health system, treatment, and total delays were $30,14,1$ and 50 days, respectively. 
Table 3 Factors Associated with Health System Delay $\geq 15$ Days Among PTB Patients in Somali Region, Eastern Ethiopia, December 2017 to October 2018, Log-Binomial Regression Model $(n=444)$

\begin{tabular}{|c|c|c|c|c|c|c|c|}
\hline \multicolumn{2}{|l|}{ Characteristics $(n=444)$} & \multirow{2}{*}{$\begin{array}{l}\text { Total PTB Cases } \\
\text { n (\%) } \\
167(37.6)\end{array}$} & \multirow{2}{*}{$\begin{array}{l}\text { HSD } \geq \text { I5 Days } \\
\text { n (\%) } \\
87(52.1)\end{array}$} & \multirow{3}{*}{$\begin{array}{l}\text { P-value } \\
0.23\end{array}$} & \multirow{2}{*}{$\begin{array}{l}\text { PR }(95 \% \mathrm{Cl}) \\
1.1(0.9,1.4)\end{array}$} & \multirow{3}{*}{$\begin{array}{l}\text { P-value } \\
0.12\end{array}$} & \multirow{2}{*}{$\begin{array}{l}\text { APR }(95 \% \mathrm{Cl}) \\
1.2(0.9,1.4)\end{array}$} \\
\hline Sex & Female & & & & & & \\
\hline & Male & $277(62.4)$ & $128(46.2)$ & & 1 & & 1 \\
\hline \multirow[t]{3}{*}{ Literacy level } & Illiterate & $274(61.7)$ & $129(47.1)$ & 0.68 & $0.9(0.7,1.3)$ & - & - \\
\hline & Formal & $112(25.2)$ & $57(50.9)$ & 0.91 & $1.0(0.7,1.4)$ & - & - \\
\hline & Tertiary & $58(13.1)$ & $29(50.0)$ & & 1 & & \\
\hline \multirow[t]{3}{*}{ Residence } & Urban & $221(49.8)$ & III (50.2) & \multirow[t]{2}{*}{0.44} & 1 & & \\
\hline & Rural & $219(49.3)$ & $102(46.6)$ & & $0.9\left(\begin{array}{lll}0.8 & 1.1\end{array}\right)$ & - & - \\
\hline & $\begin{array}{l}\text { Displaced/ } \\
\text { refugee }\end{array}$ & $4(0.9)^{\phi \phi}$ & $2^{\phi \phi}$ & - & - & & \\
\hline \multirow[t]{2}{*}{ Livelihood } & Pastoralism & $206(46.4)$ & $97(47.1)$ & \multirow[t]{2}{*}{0.6} & $0.9(0.8,1.1)$ & - & - \\
\hline & Non-pastoralism & $238(53.6)$ & $118(49.6)$ & & 1 & & \\
\hline \multirow[t]{3}{*}{ Income } & Savings & $57(12.8)$ & $32(56.1)$ & & 1 & & 1 \\
\hline & Income=expense & $309(69.6)$ & $147(47.6)$ & 0.21 & $0.8(0.7,1.1)$ & 0.19 & $0.8(0.6,1.1)$ \\
\hline & Indebt & $78(17.6)$ & $36(46.2)$ & 0.25 & $0.8(0.6,1.1)$ & 0.40 & $0.9(0.6,1.2)$ \\
\hline \multirow[t]{2}{*}{ Smoking history } & Never smoker & $399(89.9)$ & $196(49.1)$ & \multirow[t]{2}{*}{0.4} & 1 & & \\
\hline & Ever smoker & $45(10.1)$ & $19(42.2)$ & & $0.9(0.6,1.2)$ & - & - \\
\hline \multirow[t]{3}{*}{ Type of first consultation facility } & Health center & $220(49.6)$ & $130(59.1)$ & \multirow[t]{2}{*}{$<0.001$} & $1.7(1.3,2.1)$ & $<0.001$ & $1.6(1.3,2.0)$ \\
\hline & Hospital & $203(45.7)$ & $72(35.5)$ & & 1 & & 1 \\
\hline & Private clinic $^{\text {th }}$ & $21(4.7){ }^{\phi \phi}$ & $13(61.9)^{4 \phi}$ & - & - & & \\
\hline \multirow{2}{*}{$\begin{array}{l}\text { No. of healthcare providers } \\
\text { consulted }\end{array}$} & Single encounter & $137(30.9)$ & $15(11.0)$ & \multirow[t]{2}{*}{$<0.001$} & 1 & \multirow[t]{2}{*}{$<0.001$} & 1 \\
\hline & $\geq 2$ encounters & $307(69.1)$ & $200(65.1)$ & & $5.9(3.7,9.6)$ & & $5.8(3.5,9.6)$ \\
\hline \multirow[t]{2}{*}{ Smear status } & Negative & $257(57.9)$ & $140(54.5)$ & \multirow[t]{2}{*}{0.003} & $1.4(1.1,1.7)$ & \multirow[t]{2}{*}{0.05} & $1.2(1.01,1.5)$ \\
\hline & Positive & $187(42.1)$ & $75(40.1)$ & & 1 & & 1 \\
\hline \multirow[t]{2}{*}{ TB category } & New & $400(90.1)$ & $193(48.3)$ & \multirow[t]{2}{*}{0.82} & $0.96(0.7,1.3)$ & - & - \\
\hline & Retreatment & $44(9.9)$ & $22(50.0)$ & & 1 & & \\
\hline \multirow[t]{2}{*}{ Cough at first HCP consultation } & Yes & $404(91.0)$ & $190(47.0)$ & \multirow[t]{2}{*}{0.03} & $0.75(0.57,0.97)$ & 0.4 & $0.9(0.7,1.2)$ \\
\hline & No & $40(9.0)$ & $25(62.5)$ & & 1 & & 1 \\
\hline \multirow{2}{*}{$\begin{array}{l}\text { Hemoptysis at Ist HCP } \\
\text { consultation }\end{array}$} & Yes & $32(7.2)$ & $10(31.3)$ & \multirow[t]{2}{*}{0.08} & $0.6(0.4,1.1)$ & 0.6 & $0.9(0.5,1.5)$ \\
\hline & No & $412(92.8)$ & $205(49.8)$ & & 1 & & 1 \\
\hline Chest pain at first HCP & Yes & $252(56.8)$ & $|2|(48.4)$ & 0.84 & $0.98(0.8,1.18)$ & - & - \\
\hline & No & $192(43.2)$ & $94(48.9)$ & & 1 & & \\
\hline TB related symptoms at first & Two or less & $196(44.1)$ & $113(57.7)$ & 0.001 & $1.4(1.2,1.7)$ & 0.001 & $1.4(1.1,1.7)$ \\
\hline & Three or more & $248(55.9)$ & $102(4 I .1)$ & & 1 & & 1 \\
\hline
\end{tabular}

(Continued) 
Table 3 (Continued).

\begin{tabular}{|c|c|c|c|c|c|c|c|}
\hline \multicolumn{2}{|l|}{ Characteristics $(n=444)$} & \multirow{2}{*}{$\begin{array}{l}\text { Total PTB Cases } \\
\text { n (\%) } \\
65(14.6)\end{array}$} & \multirow{2}{*}{$\begin{array}{l}\text { HSD } \geq 15 \text { Days } \\
\text { n (\%) } \\
27(41.5)\end{array}$} & \multirow{2}{*}{$\begin{array}{l}\text { P-value } \\
0.18\end{array}$} & \multirow{2}{*}{$\begin{array}{l}\text { PR }(95 \% \mathrm{Cl}) \\
0.8(0.6,1.1)\end{array}$} & \multirow{2}{*}{\begin{tabular}{|l} 
P-value \\
0.06
\end{tabular}} & \multirow{2}{*}{$\begin{array}{l}\text { APR }(95 \% \mathrm{Cl}) \\
1.3(0.9,1.8)\end{array}$} \\
\hline Functional status at Ist HCP & Good & & & & & & \\
\hline & Ambulatory & $365(82.2)$ & $187(51.2)$ & & 1 & & I \\
\hline & Bedridden ${ }^{\phi \phi}$ & $14(3.2){ }^{\phi \phi}$ & $1^{\text {中巾 }}$ & - & - & - & - \\
\hline
\end{tabular}

Notes: ${ }^{\phi \phi}$ The response category is dropped out of analysis. - Not included in the final model.

Abbreviations: HCP, healthcare provider; HSD, health system delay; PR, prevalence ratio; APR, adjusted prevalence ratio; I, reference category.

Pastoralist patients experienced longer patient delays (median=35.5 days) compared to non-pastoralist complements (median=27.5 days), and it was also higher in illiterate and patients who traveled longer to reach health facilities. First visit to health center was structuralrelated; smear negativity, the manifestation of few symptoms, and multiple provider visits (could be structural) were patient-related factors associated with health system delay $\geq 15$ days.

In this study, $85.8 \%$ and half of PTB patients delayed longer than two weeks and a month without seeking medical attention, respectively. It was very excessive as the national TB control expectation is every person with a cough to visit the nearest healthcare facility within two weeks from the onset of the cough. ${ }^{4}$ It was also longer than reports in some areas of Ethiopia such as Dessie, ${ }^{25}$ West Gojjam, ${ }^{13}$ South-western, ${ }^{26}$ and Addis Ababa. ${ }^{27}$ Nonetheless, the median delay was comparable with reports in South, ${ }^{12}$ north, ${ }^{28}$ north-west,${ }^{29}$ and central ${ }^{30}$ parts of the country. The disparities might be due to contrasts in demographics, socioeconomics, access to health services, and cognitive aspects. ${ }^{31,32}$ Moreover, patient delay was notably longer among pastoralists than counterparts in the study and elsewhere. ${ }^{13,28}$ The underlying cause could be due to the limited access to healthcare in the pastoralist setups of the country, and the nature of lifestyle that forces them to move from place to place making access to healthcare difficult. ${ }^{33}$ Patients walk long hours to reach the nearby health facilities in the pastoralist setups as infrastructure is not well developed, almost all of the health posts (lowest level in the healthcare tier) and the majority of health centers in the region did not provide TB services. ${ }^{8}$ During the fieldwork, the intricacy was observed to be worse in dry seasons between January and April due to the movement of pastoralists to remote grasslands. Additional to limited access, informal providers could also contribute to longer patient delay, a quarter of patients sought informal care due to reasons such as crowdedness, lack of confidence, fear of service costs, remoteness, and bad experience in health facilities.

Half of the patients were not detected within two weeks of consultation with healthcare providers. It reveals a high degree of missed opportunities to ensure early diagnosis due to healthcare system deficiencies. The median delay of 14 days by the healthcare system was worse than reports in other parts of the country like Addis, ${ }^{27}$ Dessie, ${ }^{25}$ and Gondar ${ }^{11}$ but comparable with reports in West-Gojjam ${ }^{13}$ and south-western Ethiopia. ${ }^{26}$ In general, the combined effect of patient and health system delays inflated the median total delay in treatment to 50 days, and it reached close to a year for some patients. Cognizant of 30 days delay as the critical point of disease devastation and transmission, ${ }^{34,35}$ the highest segment of patients (82.4\%) with delay above 30 days reveals a prospect of abundant undetected and infectious cases in communities. This implies the risks of TB transmission, dissemination, death, treatment failure and drug resistance could be high in the setting as a result of excessive delays. ${ }^{15}$

Total delays were attributable to factors influencing patients' healthcare-seeking behavior and the healthcare system's efficiency to examine TB cases. The determinants of patient delay are available in a related study $;{ }^{31}$ whereas, health system delay $\geq 15$ days was associated with clinical features and first visit to health centers. Patients with mild symptoms at first presentation experienced health system delay compared to those who presented with hemoptysis, chest pain, fever, and dyspnea. This might be because providers fail to suspect TB among patients with mild illness at first visit; most of the time would misclassify it to other respiratory illnesses than TB. As reported elsewhere, ${ }^{13,25}$ health system delay $\geq 15$ days was also associated with smear negativity. Patients with smearnegative results at the initial examination are administered with antibiotics and rechecked after two weeks. ${ }^{4}$ However, 
the patients might not come on a scheduled date or opted for other facilities if negative again upon rechecking or not recovering, which causes further delay.

First visit to health centers also increased health system delay. The basis could be due to unavailability and poor quality of diagnostic services. Although they were the first points of care for half of the patients, two-third of health centers in the region did not provide laboratory services, ${ }^{8}$ and none of them possess tools to examine smear-negative cases such as X-ray or GeneXpert. Furthermore, the majority of the health centers are staffed with low- or middle-level junior professionals so that they might have skill limitations to suspect and diagnose TB cases. ${ }^{36}$ In this study, providers at frontline facilities incorrectly diagnosed $19.2 \%$ of smearpositive as smear-negative patients. Thus, the health system delays could have resulted from poor competency of providers and low capacity of health facilities to diagnose TB cases.

However, the extent of delay might be underestimated as a result of recall and misrepresentation biases. Patients are likely to recall the date when the illness gets severe but not the exact date of onset, and if pastoralists were represented proportionally, the patient delay could have increased.

\section{Conclusion}

This study highlights that timely detection and treatment of pulmonary tuberculosis remains a serious challenge in the Somali pastoral setting of Ethiopia. Over half of pulmonary TB patients delayed longer than seven weeks without obtaining treatment, which is attributable to patient and health system delays with a certain inclination to patient delay. The extended delays reveal the magnitude of undetected TB cases could be great in communities, and thus the leading cause of low case detection rates in the region for years in a row. Delays were associated with clinical, sociodemographic, service accessibility and availability factors that affect the healthcare-seeking of patients, skill of healthcare providers and capacity of healthcare facilities. Hence, expansion of TB services better tailored to pastoralists including mobile services and community engagement can be helpful to reduce patient delays; whereas, availing diagnostic services at health centers, delivering better equipment, and enhancing the competency of frontier providers can be effective strategies to tackle health system delays.

\section{Abbreviations}

AFB, acid-fast bacilli; AHRI, Armauer Hansen Research Institute; APR, adjusted prevalence ratio; CI, confidence interval; DOTS, Directly Observed Therapy-Short Course;
FMOH, Federal Ministry of Health; HIV, human immunodeficiency virus; IQR, inter-quartile range; MDR, multidrug resistant; NTP, national TB control program; PR, Prevalence Ratio; PTB, pulmonary tuberculosis; TB, tuberculosis; WHO, World Health Organization.

\section{Data Sharing Statement}

The data supporting the conclusions of this article are included in the article. The collected data contain confidential information, and consent has not been obtained for public sharing of raw data with identifiers. However, the datasets analyzed are available at the hands of the corresponding author and can be shared upon reasonable requests.

\section{Ethical Approval and Informed Consent}

This study was conducted in accordance with the Declaration of Helsinki. The protocol was approved by Institutional Health Research Ethics Review Committee (IHRERC) of Haramaya University (Ref.No: IHRERC/009/2016), and AHRI/ALERT Ethical Review Committee (Ref.No: P001/ 17). Written consent was obtained after appropriate information was provided for participants and parents/guardians of 15-17 years old participants. Participation was voluntarily and withdrawal was guaranteed.

\section{Acknowledgment}

We are very thankful to Haramaya University and AHRI for protocol evaluation and ethical approval. Our special gratitude goes to Somali Regional Health Bureau and the respective study facilities for their support during data collection including transport and logistic support and permitting TB care providers' engagement in data collection. Our sincere gratefulness also goes to TB care for their vigilant effort in the data collection process.

\section{Author Contributions}

All authors made substantial contributions to conception and design, acquisition of data, or analysis and interpretation of data; took part in drafting the article or revising it critically for important intellectual content; gave final approval of the version to be published; and agree to be accountable for all aspects of the work.

\section{Funding}

This study was funded by the Swiss Agency for Development and Cooperation (SDC) in the frame of the 
Jigjiga One Health Initiative (JOHI) and Jigjiga University. Swiss Tropical and Public Health Institute and Armauer Hansen Research Institute also provided logistic support. Funding bodies had no role in the design, collection, analysis, and interpretation of findings.

\section{Disclosure}

None of the authors have any competing interests.

\section{References}

1. WHO. Global Tuberculosis Report 2019. Geneva: World Health Organization; 2019.

2. Kebede AH, Alebachew Z, Tsegaye F, et al. The first populationbased national tuberculosis prevalence survey in Ethiopia, 2010-2011. IJTLD. 2014;18(6):635-639. doi:10.5588/ijtld.5513.0417

3. Lönnroth K, Raviglione M. The WHO's new End TB Strategy in the post-2015 era of the Sustainable Development Goals. Trans $R$ Soc Trop Med Hyg. 2016;110(3):148-150. doi:10.1093/trstmh/trv108

4. FMOH. National Guidelines for TB, DR-TB and Leprosy in Ethiopia. Edited by Ethiopia FMOHo. 6th ed. Addis Ababa; 2017.

5. Ho J, Fox GJ, Marais BJ. Passive case finding for tuberculosis is not enough. Int $J$ Mycobacteriol. 2016;5(4):374-378. doi:10.1016/j. ijmyco.2016.09.023

6. Tadesse T, Demissie M, Berhane Y, Kebede Y, Abebe M. Two-Thirds of Smear-Positive Tuberculosis Cases in the Community Were Undiagnosed in Northwest Ethiopia: population Based Cross-Sectional Study. PLoS One. 2011;6(12):e28258. doi:10.1371/journal.pone.0028258

7. Hamusse S, Demissie M, Teshome D, Hassen MS, Lindtjorn B. Prevalence and Incidence of Smear-Positive Pulmonary Tuberculosis in the Hetosa District of Arsi Zone, Oromia Regional State of Central Ethiopia. BMC Infect Dis. 2011;6(12):214. doi:10.1186/s12879-0172321-0

8. RHB. Regional Health Services Coverage for the Year 2010 Ethiopian Calender. Jigjiga: Regional Health Bureau; 2019.

9. Getnet F, Demissie M, Assefa N, Mengistie B, Worku A. Delay in diagnosis of pulmonary tuberculosis in low-and middle-income settings: systematic review and meta-analysis. BMC Pulm Med. 2017;17 (1):202. doi:10.1186/s12890-017-0551-y

10. Li Y, Ehiri J, Tang S, et al. Factors associated with patient, and diagnostic delays in Chinese TB patients: a systematic review and meta-analysis. BMC Med. 2013;11(1):156. doi:10.1186/1741-7015-11-156

11. Bogale S, Diro E, Shiferaw AM, Yenit MK. Factors associated with the length of delay with tuberculosis diagnosis and treatment among adult tuberculosis patients attending at public health facilities in Gondar town, Northwest, Ethiopia. BMC Infect Dis. 2017;17 (1):145. doi:10.1186/s12879-017-2240-0

12. Asefa A, Teshome W. Total delay in treatment among smear positive pulmonary tuberculosis patients in five primary health centers, southern Ethiopia: a cross sectional study. PLoS One. 2014;9(7):e102884. doi:10.1371/journal.pone. 0102884

13. Gebreegziabher SB, Bjune GA, Yimer SA. Patients' and health system's delays in the diagnosis and treatment of new pulmonary tuberculosis patients in West Gojjam Zone, Northwest Ethiopia: a cross-sectional study. BMC Infect Dis. 2016;16(1):673. doi:10.1186/s12879-016-1995-z

14. Gele AA, Bjune G, Abebe F. Pastoralism and delay in diagnosis of TB in Ethiopia. BMC Public Health. 2009;9(1):5. doi:10.1186/1471-2458-9-5

15. Gebreegziabher SB, Bjune GA, Yimer SA. Total Delay Is Associated with Unfavorable Treatment Outcome among Pulmonary Tuberculosis Patients in West Gojjam Zone, Northwest Ethiopia: A Prospective Cohort Study. PLoS One. 2016;11(7):e0159579. doi:10.1371/journal.pone.0159579
16. Cheng S, Chen W, Yang Y, et al. Effect of Diagnostic and Treatment Delay on the Risk of Tuberculosis Transmission in Shenzhen, China: an Observational Cohort Study, 1993-2010. PLoS One. 2013;8(6): e67516. doi:10.1371/journal.pone.0067516

17. Veesa KS, John KR, Moonan PK, et al. Diagnostic pathways and direct medical costs incurred by new adult pulmonary tuberculosis patients prior to anti-tuberculosis treatment - Tamil Nadu, India. PLoS One. 2018;13(2):e0191591. doi:10.1371/journal.pone.0191591

18. CSA. Population Projection of Ethiopia for All Regions: At Wereda Level from 2014 - 2017. Addis Ababa: Central Statistical Agency of Federal Democratic Republic of Ethiopia; 2013.

19. Montavon A, Jean-Richard V, Bechir M. Health of mobile pastoralists in the Sahel - assessment of 15 years of research and development. Trop Med Int Health. 2013;18(9):1044-1052. doi:10.1111/ tmi. 12147

20. Gele AA, Sagbakken M, Abebe F, Bjune GA. Barriers to tuberculosis care: a qualitative study among Somali pastoralists in Ethiopia. BMC Res Notes. 2010;3(1):86. doi:10.1186/1756-0500-3-86

21. WHO. Diagnostic and Treatment Delay in Tuberculosis. An In-Depth Analysis of the Health-Seeking Behaviour of Patients and Health System Response in Seven Countries of the Eastern Mediterranean Region; 2006. WHO-EM/TDR/009/E/10.06/1000.

22. Hussen A, Biadgilign S, Tessema F, Mohammed S, Deribe K, Deribew A. Treatment delay among pulmonary tuberculosis patients in pastoralist communities in Bale Zone, Southeast Ethiopia. BMC Res Notes. 2012;5(1):320. doi:10.1186/1756-0500-5-320

23. Mesfin MM, Newell JN, Walley JD, Gessessew A, Madeley RJ. Delayed consultation among pulmonary tuberculosis patients: a cross sectional study of 10 DOTS districts of Ethiopia. BMC Public Health. 2009;9(1):53. doi:10.1186/1471-2458-9-53

24. Mfinanga SG, Mutayoba BK, Kahwa A, et al. The magnitude and factors associated with delays in management of smear positive tuberculosis in Dar es Salaam, Tanzania. BMC Health Serv Res. 2008;8(1):158. doi:10.1186/1472-6963-8-158

25. Seid A, Metaferia Y. Factors associated with treatment delay among newly diagnosed tuberculosis patients in Dessie city and surroundings, Northern Central Ethiopia: a cross-sectional study. BMC Public Health. 2018;18(1):931. doi:10.1186/s12889-018-5823-9

26. Asres A, Jerene D, Deressa W. Delays to anti-tuberculosis treatment intiation among cases on directly observed treatment short course in districts of southwestern Ethiopia: a cross sectional study. BMC Infect Dis. 2019;19(1):481. doi:10.1186/s12879-019-4089-x

27. Adenager GS, Alemseged F, Asefa H, Gebremedhin AT. Factors associated with treatment delay among pulmonary tuberculosis patients in public and private health facilities in Addis Ababa, Ethiopia. Tuberc Res Treat. 2017;2017.

28. Alema HB, Hailemariam SA, Misgina KH, et al. Health care seeking delay among pulmonary tuberculosis patients in North West zone of Tigrai region, North Ethiopia. BMC Infect Dis. 2019;19(1):309. doi:10.1186/s12879-019-3893-7

29. Kahsay A, Gedefaw M, Asres M, Weldu Y. Patients' delay in seeking health care for tuberculosis diagnosis in East Gojjam Zone, Northwest Ethiopia. Am J Trop Med Hyg. 2017;96(5):1075. doi:10.4269/ajtmh.16-0892

30. Wondawek TM, Ali MM. Delay in treatment seeking and associated factors among suspected pulmonary tuberculosis patients in public health facilities of Adama town, eastern Ethiopia. BMC Public Health. 2019;19(1):1527. doi:10.1186/s12889-019-7886-7

31. Getnet F, Demissie M, Worku A, et al. Determinants of patient delay in diagnosis of pulmonary tuberculosis in Somali Pastoralist Setting of Ethiopia: a matched case-control study. Int J Environ Res Public Health. 2019;16(18):3391. doi:10.3390/ijerph16183391

32. Fekadu L, Hanson C, Osberg M, Makayova J, Mingkwan P, Chin D. Increasing access to tuberculosis services in ethiopia: findings from a patient-pathway analysis. J Infect Dis. 2017;216(supp1_7):S696S701. doi:10.1093/infdis/jix378 
33. Nooh F, Crump L, Hashi A, et al. The impact of pastoralist mobility on tuberculosis control in Ethiopia: a systematic review and meta-synthesis. Infect Dis Poverty. 2019;8(1):73. doi:10.1186/ s40249-019-0583-z

34. Getnet F, Demissie M, Worku A, et al. Delay in diagnosis of pulmonary tuberculosis increases the risk of pulmonary cavitation in pastoralist setting of Ethiopia. BMC Pulm Med. 2019;19(1):201. doi:10.1186/s12890-019-0971-y
35. Lin X, Chongsuvivatwong V, Lin L, Geater A, Lijuan R. Dose-response relationship between treatment delay of smear-positive tuberculosis patients and intra-household transmission: a cross-sectional study. Trans $R$ Soc Trop Med Hyg. 2008;102(8):797-804. doi:10.1016/j.trstmh.2008.04.027

36. Sima BT, Belachew T, Abebe F. Health care providers' knowledge, attitude and perceived stigma regarding tuberculosis in a pastoralist community in Ethiopia: a cross-sectional study. BMC Health Serv Res. 2019;19(1):19. doi:10.1186/s12913-018-3815-1

\section{Publish your work in this journal}

Risk Management and Healthcare Policy is an international, peerreviewed, open access journal focusing on all aspects of public health, policy, and preventative measures to promote good health and improve morbidity and mortality in the population. The journal welcomes submitted papers covering original research, basic science, clinical \& epidemiological studies, reviews and evaluations, guidelines, expert opinion and commentary, case reports and extended reports. The manuscript management system is completely online and includes a very quick and fair peer-review system, which is all easy to use. Visit http://www.dovepress.com/testimonials.php to read real quotes from published authors. 